Canadian

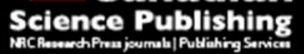

Canadian Journal of Civil Engineering Revue canadienne de génie civil

Investigations on the Dynamics of Particle Clouds in Stagnant Water Using Response Surface Methodology

\begin{tabular}{|r|l|}
\hline Journal: & Canadian Journal of Civil Engineering \\
\hline Manuscript ID & cjce-2016-0379.R1 \\
\hline Manuscript Type: & Article \\
\hline Date Submitted by the Author: & 21 -Oct-2016 \\
\hline Complete List of Authors: & $\begin{array}{l}\text { Pakzad, Leila; Lakehead University, Chemical Engineering } \\
\text { Azimi, Amir; Lakehead University, Civil Engineeering }\end{array}$ \\
\hline Keyword: & $\begin{array}{l}\text { Analysis of variance, Response surface methodology, Turbulent jets, } \\
\text { Particle cloud }\end{array}$ \\
\hline \multicolumn{2}{|l}{} \\
\hline
\end{tabular}

SCHOLARONE ${ }^{\text {IM }}$

Manuscripts 


\title{
Investigations on the Dynamics of Particle Clouds in Stagnant Water Using Response Surface Methodology
}

\author{
Leila Pakzad $^{1}$, Amir H. Azimi (corresponding author) ${ }^{2}$
}

\footnotetext{
${ }^{1}$ Assistant Professor, Dept. of Chemical Engineering, Lakehead University, Thunder Bay ON, Canada P7B 5E1. Email: 1pakzad@lakeheadu.ca

${ }^{2}$ Assistant Professor, Dept. of Civil Engineering, Lakehead University, Thunder Bay ON, Canada P7B 5E1. Email: azimi@lakeheadu.ca

Tel: 807-343-8560
} 


\begin{abstract}
Disposal of sediments during land reclamation and dredging is an important component in many environmental engineering projects. Dredged material can be discharged into the ambient water either instantaneously to form a particle cloud or continuously to form a slurry jet. This paper presents the results of a laboratory experiments to understand the dynamics of particle cloud in stagnant water. Different independent parameters such as particle size, nozzle diameter, cumulative mass of sand particles, and release height were tested. Due to wide ranges of selected variables and interactions between parameters, response surface methodology (RSM) technique was employed to determine the importance and effectiveness of each parameter on the growth and motion of particle clouds. A narrow range of non-dimensional cloud buoyancy in thermal regime was selected for design of experiments. Particle size was found to be the most significant parameter for the response predictions. RSM results showed that increasing the nozzle diameter from $5 \mathrm{~mm}$ to $14 \mathrm{~mm}$ slightly increased the cloud width if all other parameters kept unchanged. Statistical analysis of results indicated that the effect of the release height on growth of particle cloud was not significant; however, it was effective on variations of frontal velocity.
\end{abstract}

Keywords: Analysis of variance, Central composite design, Mixing, Particle cloud, Response surface methodology, Sand jet, Turbulent jets, Two-phase flows. 


\section{Introduction}

Many parameters such as fluid characteristics, length and time scales, temperature, and viscosity are involved to understand and optimize discharge of effluents using turbulent jets/plumes (Fischer et al. 1979). Dredged material can be discharged into the ambient water either instantaneously to form a particle cloud or continuously to form slurry jets/plumes. To study particle clouds and sediment-laden jets/plumes, number of additional parameters such as sand particle size, particle size distribution, shape of sand particles, initial sand velocity, and sand concentration increase the complexity of the problem by generating more interactions among involved parameters (Azimi et al. 2011, 2012a, 2012b, and 2014; Lai et al. 2016a, 2016b). Selection of suitable ranges of variables and understanding the interactions among them are unknown a priori. Therefore, in most cases, large numbers of experiments are required to provide a clear understanding about the significance of each variable. Recently, extensive laboratory experiments and numerical modeling were conducted to analyze and understand the dynamics of particle clouds and slurry jets/plumes in stagnant water (Lai et al. 2013, 2015, 2016a, 2016b; Wang et al. 2014, and 2015; Zhao et al. 2012, 2014). Active research in this area indicates that the effects of controlling parameters on dynamics of particles is complex, highly non-linear, and requires more attention.

Applying the classical one factor at a time approach is not only a time consuming method for such multivariable systems but also it is not suitable to study the interactions among different variables. In order to overcome this challenge, factorial design of experiments (DOE) was employed. This statistical method significantly reduces the number of experiments and it is capable of considering the effects of many parameters and their interactions. DOE employs statistical techniques such as response surface methodology (RSM) to simultaneously consider several factors at different levels (Montgomery 2012). In addition, conducting many detailed laboratory experiments using particle image velocimetry (PIV) technique and computational fluid dynamics (CFD) require extensive time and resources to define the importance of variables and their interactions (Azimi et al. 2011, 2012a). Therefore, a combination of preliminary experiments with the RSM modeling can help researchers and modelers to identify the sensitivity 
of each parameter and define the range of variables before performing detailed laboratory experiments and numerical simulations.

Response surface methodology has been extensively used in the field of civil engineering for experimental design, statistical analysis, and optimization (Deng and Cai 2010; Haghshenas et al 2014; Mollon et al 2009). In particular, DOE can be applied in tailings management since tailings characteristics in most oil-sand and mining industries varies during mining operation and predictions of particle cloud in such systems are challenging. Therefore, factorial design of experiments can be employed for monitoring of tailings and optimization of tailings management. Available field data such as effluent characteristics and deposition profiles can be grouped together to be suitable for RMS modeling. The outcome of DOE regression models can be used to understand the importance and effectiveness of each parameter and the results can be used for monitoring and optimization.

In multi-phase flow dynamics, different phenomena occur depending upon the controlling parameters such as, particle concentration and relative size of the particles, and the generated vortices in the ambient water (Gore and Crowe 1989; Crowe 2000; Azimi et al. 2012b). Effects of particle size, nozzle diameter and mass of particles on dynamics of particle cloud were studied using dimensional analysis. Two distinctive flow classifications were identified named as turbulent thermal and swarm regimes (Batchelor 1954; Morton et el. 1956; Noh and Fernando 1993; and Bush et al. 2003). Particle cloud in turbulent thermal regime flows and spreads due to the existence of cloud buoyancy. In this regime particle-particle interactions and the wake generated by the frontier particles play important roles in particle dynamics. Once particle cloud spreads to its maximum size, effect of particle-particle interactions becomes less significant and particles settle individually with a constant settling velocity. Particle clouds at this stage are called swarm. The settling velocity of swarm of particles is close to the settling velocity of individual particles $u_{\infty}$ (Morton et el. 1956).

In this study, effect of four controlling parameters on cloud dynamics were studied using laboratory experiments and RSM modeling. The outcomes of the statistical model were also compared with empirical correlations from dimensional analysis. Similar technique can be applied to evaluate the effects of other parameters such as sand concentration, particle size distribution, particle shape, and etc. 


\section{Dimensional Analysis}

Dimensional analysis has been employed predominantly to reduce the number of parameters that need to be studied. This technique allows the use of experimental data to be used in work of other scales (Wang et al. 2015). Dimensional analysis forms a group of non-dimensional numbers such as Reynolds number $\mathrm{R}=\rho_{w} u_{o} d_{o} / \mu$, densimetric Froude number $\mathrm{F}=$ $u_{o} /\left(g D_{50}\left(\rho_{s}-\rho_{w}\right) / \rho_{w}\right)^{1 / 2}$, where $u_{o}$ is the initial sand velocity, $d_{o}$ is the nozzle size, $\rho_{w}$ is the density of water, $\rho_{s}$ is the density of sand particles, $\mu$ is the dynamic viscosity of water, and $g$ is the acceleration due to gravity, and aspect ratio between two length/time scales. In the present experimental study, the parameters that control the width $w$ and the fontal velocity of particle clouds in stagnant water $u_{f}$ are

$$
w, u_{f}=f_{1}\left(x, d_{o}, D_{50}, u_{o}, \mu, g, \rho_{s}, \rho_{w}, c_{o}, m, h\right)
$$

where $x$ is the axial distance from the cloud's front and the nozzle (see Figure 1) and $c_{o}$ is the initial volumetric sand concentration. A vessel full of unpacked sand grains contains $60 \%$ of solid volume and $40 \%$ of void space so, the volumetric concentration of unpacked sand particles in a container is $c_{o}=0.6 \mathrm{vol} / \mathrm{vol}$ (Azimi et al. 2012a; Lai et al. 2016b). The evolution of a particle cloud can be related to the cloud buoyancy $Q$ (Bush et al. 2003) as

$$
Q=\frac{V_{o} g\left(\rho_{s}-\rho_{w}\right)}{\rho_{w}}
$$

where $V_{o}$ is the total volume of the particles and it can be expressed as $V_{o}=m /\left(\rho_{s} c_{o}\right)$. For particle cloud system, previous experimental studies identified two distinct regimes of a turbulent thermal and a swarm (Batchelor 1954; Morton et el. 1956; Noh and Fernando 1993; and Bush et al. 2003). Dynamics of the cloud of particles were found to be completely different for these two regimes. Bush et al. (2003) experimentally showed that the frontal velocity of the turbulent thermal can be expressed by $Q, u_{\infty}$, and $x$ where $u_{\infty}$ is the terminal settling velocity of individual particles and it can be estimated using the Stokes formula (Gore and Crowe 1989) as

$$
u_{\infty}=\frac{g\left(\rho_{s}-\rho_{w}\right) D_{50}^{2}}{18 \mu}
$$


For time-variant flows, the terminal settling velocity of particles $u_{\infty}$ can be estimated using an empirical equation (Dietrich 1982), or the Haywood tables (Holdich 2002). Bush et al. (2003) introduced a scaling relationship for turbulent thermal as

$u_{f}=f_{2}\left(Q^{1 / 2}, x^{-1}, u_{\infty}^{-1}\right)$

They reported that the non-dimensional cloud buoyancy, $Q /\left(x^{2} u_{\infty}{ }^{2}\right)$ can be used as a controlling parameter to define the turbulent thermal and swarm regimes. In thermal regime, the normalized frontal velocity $u_{f} / u_{\infty}$ increases as the non-dimensional cloud buoyancy increases whereas the normalized frontal velocity finally reaches a plateau in swarm regime (Noh and Fernando 1993; and Bush et al. 2003). Recent experimental studies on sand jets front indicated that in the swarm regimes the cloud velocity was five times greater than the terminal settling velocity of individual particle $\left(u_{\infty}\right)$ (Azimi et al. 2012b). However, Buhler and Papantoniou (2001) defined $1.4 u_{\infty}$ as threshold of cloud frontal velocity to classify thermal and swarm regimes. For most particle cloud systems, the non-dimensional cloud buoyancy varies within five orders of magnitudes ranging from 0.001 to 100 . Bush et al. (2003) showed that the particle cloud behaves as a turbulent thermal for $Q /\left(x^{2} u_{\infty}{ }^{2}\right) \geq 0.1$ and it descends as a swarm for $Q /\left(x^{2} u_{\infty}{ }^{2}\right)<0.1$.

Figure 2 shows examples of swarm and turbulent thermal for the present experimental tests at 3 seconds after release of sand particles. The non-dimensional cloud buoyancy, $Q /\left(x^{2} u_{\infty}{ }^{2}\right)$ was found to be a suitable parameter to classify the hydrodynamics of particle cloud. Figure 2 a shows the swarm of particles with $Q /\left(x^{2} u_{\infty}{ }^{2}\right)=0.024$ which is less than 0.1 and Figure $2 \mathrm{~b}$ shows the turbulent thermal with $Q /\left(x^{2} u_{\infty}{ }^{2}\right)=0.58$. In swarm condition, particle-particle interactions are insignificant (Crowe 2000) and the frontal velocity of the cloud is constant and it is comparable with the terminal settling velocity of the individual sand particles (Bush et al. 2003). In turbulent thermal regime, Bush et al. (2003) showed that the frontal velocity of particle cloud increased with the non-dimensional cloud buoyancy, $Q /\left(x^{2} u_{\infty}{ }^{2}\right)$ as

$$
\frac{u_{f}}{u_{\infty}}=(3 \pm 0.4)\left(\frac{Q}{x^{2} u_{\infty}^{2}}\right)^{1 / 2}
$$

Depends on the initial conditions of the tests such as particle size and cumulative mass of sand particles, spread of particle cloud and its frontal velocity would be different for similar time 
duration of particle cloud motion in water. For example, for constant time duration from the onset of release, particle cloud behaves like a turbulent thermal for tests with large particle mass and small particle size and the frontal velocity of particle cloud increases with the nondimensional cloud buoyancy (see Eq. (5)). Whereas, at similar time duration from the onset of release, particle cloud descends as a swarm of individual particles with relatively constant frontal velocity for tests with small particle mass and large particle size. Therefore, it is critical to understand the physics of the problem before conducting any statistical analysis.

\section{Methodology}

\section{Design of Experiments (DOE)}

The traditional approach to evaluate the effect of a single variable on the objective response(s) while keeping the other variables constant is time consuming. By applying the statistical design of experiments, the number of experiments decreases considerably. The response surface methodology (RSM), a combination of mathematical and statistical techniques, is employed to provide a more optimal process design of the experiments and data analysis. Different types of RSM design can be applied such as central composite design (CCD) (Box-Wilson 1951), BoxBehnken design (BBD) (Box and Behenken 1960), and D-Optimal designs (Myers and Montgomery 2002). CCD uses five fractional factorial coded levels to calculate the second order of the response surfaces (see Tables 1 and 3). The main core of the CCD experimental design is the combination of fractional factorial or factorial and central points.

The CCD method was selected to analyze the sensitivity and importance of the parameters selected in this study on the dynamics of particle clouds. Recently, the response surface methodology (RSM) has been used as a reliable tool for model optimization in the field of water and environmental engineering (Ghafoori et al. 2014; Kirmizakis et al. 2014; and Yahyapour et al. 2014). Pakzad et al. (2013) used RSM to verify the optimal process design for mixing of a non-Newtonian biopolymer solutions in a reactor equipped with coaxial mixers. Four different parameters named as mixture concentration, coaxial configuration, anchor speed, and the central impeller speed were selected as independent variables. They found that the RSM model can adequately describe the mixing time and the specific power consumption as the model responses. Kirmizakis et al. (2014) provided a suitable example of model optimization by applying the 
RSM technique to improve the quality of landfill leachate through COD (chemical oxygen demand) removal. Similarly, the removal of total suspended solids (TSS) and turbidity by vegetation were optimized through RSM statistical technique (Yahyapour et al. 2014). It was found that the flow velocity, vegetation density, and the length of vegetation are the most important effective parameters. Although the RSM model can find strong statistical correlations among various parameters, great care should be taken to understand the fundamental physics of the phenomena before employing such statistical model for experimental design.

CCD statistical model was employed to investigate the effects of four independent variables $\left(X_{I}=\right.$ $D_{50}, X_{2}=d_{o}, X_{3}=m$, and $\left.X_{4}=h\right)$ on the response functions $\left(Y_{1}=w\right.$, and $\left.Y_{2}=u_{f}\right)$ and seven replicates at the central point with a code level of zero (see Tables 1 and 3 ) and with the values of $D_{50}=0.389$ $\mathrm{mm}, d_{o}=10 \mathrm{~mm}, m=6 \mathrm{~g}$, and $h=200 \mathrm{~mm}$ were carried out to estimate the experimental error. The independent variables were coded at five levels between -2 and +2 as presented in Table 1 . The ranges of the four variables were selected based on a set of preliminary experiments (Bush et al. 2003; Azimi et al. 2012a; Azimi et al. 2014). The data from CCD method can be fitted into the following quadratic function as

$$
Y=\beta_{o}+\sum_{i=1}^{k} \beta_{i} X_{i}+\sum_{i=1}^{k} \beta_{i i} X_{i}^{2}+\sum_{i=1}^{j-1} \sum_{j=1}^{k} \beta_{i j} X_{i} X_{j}+e_{i}
$$

where $Y$ is the predicted response (here, $Y_{1}=w$, and $\mathrm{Y}_{2}=u_{f}$ ), $X_{i}$ and $X_{j}$ are independent variables, $\beta_{o}$ is a constant coefficient (i.e., intercept term), $\beta_{i}$ refers to the effect of the parameter in the response (i.e., linear term), $\beta_{i j}$ represents the effect of interaction among variables $i$ and $j, \beta_{i i}$ is related to the shape of the curve (i.e., quadratic effect), $k$ is the number of studied factors and $k=4$ (i.e., $X_{1}, X_{2}, X_{3}$, and $X_{4}$ ) in this study. $e_{i}$ is the error residual countenancing uncertainties between the observed and predicted values.

Trial version of Design-Expert 9 (Stat-Ease, Inc.) was employed for the regression analysis and the coefficient estimation of the response functions. The adequacy of the equations in terms of statistical significance of the models was assessed by the fisher's F-test for analysis of variance (ANOVA). Three-dimensional surface and two-dimensional contour plots were obtained while keeping the other variables constant in the quadratic models. The experimental and predicted values from quadratic models were compared for model verification. 


\section{Experimental Setup}

Laboratory experiments were conducted in a $0.40 \mathrm{~m}$ square glass tank filled with tap water. The water depth was fixed at $0.97 \mathrm{~m}$ from the bottom of the tank in all tests. Effects of particle size $D_{50}$ nozzle diameter $d_{o}$ particle mass $m$ and release height $h$ on the hydrodynamic behaviour of particle cloud were investigated. The release height was selected to study the effect of initial velocity of particles on cloud dynamics. Five brass nozzles with a nominal diameter of $d_{o}=5,8$, 10,12 , and $14 \mathrm{~mm}$ were selected. The nozzle was connected to a short pipe with a diameter of 25 $\mathrm{mm}$ and a length of $200 \mathrm{~mm}$. The nozzle and the pipe system were installed on a steel frame to adjust the location of the nozzle at different height from the water surface. A minimum release distance of $5 \mathrm{~mm}$ was kept above the water surface to avoid clogging of sand particles inside the nozzle. Vertical distance from the nozzle $x$ was measured from the water surface. A schematic view of the experimental setup and the coordinate system is shown in Figure 1. Five different heights of $h=0,100,200,300$, and $400 \mathrm{~mm}$ were selected to study the effect of initial sand velocity on the hydrodynamic characteristics of sand jets. Five sand particle sizes were chosen with a median diameter of $D_{50}=0.1375,0.196,0.389,0.507$, and $0.595 \mathrm{~mm}$ and density of $\rho_{s}=$ $2540 \mathrm{~kg} / \mathrm{m}^{3}$. Experimental details and the related non-dimensional parameters are listed in Table 2. Experimental study on descending of sand particle cloud indicated that the characteristic dimensions and mixing strength of particle cloud depend upon the initial mass of particles (Noh and Fernando 1993; Bush et al. 2003). Accordingly, five different masses of particles with a total mass of $1,3,6,12$, and $18 \mathrm{~g}$ were selected. The frontal position and the cloud width were determined using the same image analysis method applied by Azimi et al. (2012a).

A CCD camera (Prosilica GT 1910c, Edmonds Optics, Inc.) with a resolution of 1920x1080 pixels was used. The camera was controlled by a computer frame grabber software (AVT Vimba Viewer v.1.1.3) captured images of the sand cloud with a speed of 20 frames per second and a resolution of $3.84 \mathrm{pixel} / \mathrm{mm}$. The area of interest was a rectangle of $500 \mathrm{~mm} \times 280 \mathrm{~mm}$ and located at the air-water interface. Repeatability tests were conducted seven times and the cloud width $w$ and the frontal velocity $u_{f}$ were measured for each test. In thermal condition, the maximum errors were approximately $\pm 6.5 \%$ and $\pm 6 \%$ for $w$ and $u_{f}$, respectively. The uncertainties were decreased for the swarm condition to $\pm 3 \%$ and $\pm 4 \%$ for $w$ and $u_{f}$, respectively.

\section{Results and Discussion}




\section{Evaluation of response surface method}

Performance of RSM was verified using an empirical formulation proposed by Azimi et al. (2012a) to predict the frontal velocity of sand jet. CCD method was used to evaluate the effects of two independent variables $\left(X_{1}=d_{o}\right.$ and $\left.X_{2}=x\right)$ on the response function of frontal velocity $\left(Y_{l}=u_{f}\right)$. Details of the experimental range and levels of the independent variables for validation purpose are listed in Table 3. Overall, nine samples were extracted from empirical formulation as shown in Table 4 and the results were compared with the predictions of the statistical model. Azimi et al. (2012a) found that the frontal velocity of the sand jet in turbulent thermal regime is predicted by

$$
\frac{u_{f}}{u_{\infty}}=-\frac{1}{4}\left(\frac{D_{50}}{d_{o}}\right)^{-0.75} \ln \left(\frac{x}{d_{o}}\right)+3.8\left(\frac{D_{50}}{d_{o}}\right)^{-0.55}
$$

The proposed empirical formula (Eq. (7)) was tested for $D_{50}=0.206 \mathrm{~mm}$, nozzle diameter $d_{o}$ ranging from $2 \mathrm{~mm}$ to $10 \mathrm{~mm}$, and a non-dimensional distance $x / d_{o}$ ranging from 0 to 400 . Five different nozzle diameters of 2, 3, 4, 4.75, and $10 \mathrm{~mm}$ were selected and the frontal velocities were calculated using Eq. (7). The present experimental data were conducted at a maximum distance of $x=800 \mathrm{~mm}$ from the nozzle. Accordingly, the distance range $x$ was selected from 50 $\mathrm{mm}$ to $750 \mathrm{~mm}$ providing $x / d_{o}$ ranging from 12.5 to 187.5 (see Table 4 for $x / d_{o}$ range). Related parameters for evaluation of the RSM model for the validation section are listed in Table 4.

Figure 3 shows the three-dimensional response surface of the frontal velocity and its interaction effects with $d_{o}$ and $x$. As can be seen in Figure 3, the frontal velocity of sand jet decreased with increasing $x$ and variations of the frontal velocity was more pronounced for the larger nozzle diameter. Negative exponent in Eq. (7) indicates an inverse relationship between $x$ and $u_{f}$. As can be seen in Figure 3, far from the nozzle at $x=750 \mathrm{~mm}$, effect of nozzle diameter on the frontal velocity becomes less significant. The RSM model proposed for these tests shows a non-linear relationship among $u_{f}, d_{o}$, and $x$ as

$u_{f}=152.07+29.6 d_{o}-0.170 x-0.019 d_{o} x-0.576 d_{o}^{2}+1.47 \times 10^{-4} x^{2}$

Comparison between the RSM model and empirical equation shows that the RSM model predicted the trend properly by showing non-linear velocity drop with the axial distance from the 
nozzle. The RSM model predicted the frontal velocity with a maximum $\pm 10 \%$ error in comparison with the empirical equation. The uncertainties of prediction far from the nozzle $\left(x / d_{o} \approx 250\right)$ for tests with $d_{o}=2 \mathrm{~mm}$ and $10 \mathrm{~mm}$ were $\pm 1.5 \%$ and $\pm 12 \%$, respectively. Magnitudes of the errors indicate that the statistical models are useful tools to predict responses and to determine the importance of the interactions among the independent variables.

\section{Multiple regression modeling}

It is worth mentioning that the responses (i.e. $w$ and $u_{f}$ ) measured in each test varied with time. Both turbulent thermal and swarm regimes with normalized cloud buoyancy of $0.008<Q /\left(x^{2} u_{\infty}{ }^{2}\right)<105.5$ were found for all tests. Experimental observations on sand jet front (Azimi et al. 2012a) indicated that $w$ increased with time while $u_{f}$ gradually decreased and both responses reached a plateau far from the nozzle. In the present study, the responses were measured at two different times of $t=1 \mathrm{~s}$ and $t=2.5 \mathrm{~s}$ after the release of particles. Based on the value of the independent variables, both thermal and swarm regimes were formed within the defined time of $1 \mathrm{~s}<t<2.5 \mathrm{~s}$. Statistical analysis of data taken at $t=1 \mathrm{~s}$ did not show the significance of the relative forces, since in most tests particle clouds were in turbulent thermal regime. The corresponding normalized cloud buoyancy for $t=1 \mathrm{~s}$ was in the range of $0.08<Q /\left(x^{2} u_{\infty}{ }^{2}\right)<2.08$. For $t=1 \mathrm{~s}$, all measurements were taken from the turbulent thermal regime $Q /\left(x^{2} u_{\infty}{ }^{2}\right)>0.1$. The fit of the model was controlled by the coefficient of determination $\mathrm{R}^{2}$. In this condition, the $\mathrm{R}^{2}$ values of $w$ and $u_{f}$ were 0.9291 and 0.8961 , respectively.

The physical significance of the thermal and swarm regimes was more pronounced for longer release times (i.e., $t=2.5 \mathrm{~s}$ ). In this case, depends on the size and mass of particles, particle cloud could be either in thermal or in swarm regimes. The values of the normalized cloud buoyancy for $t=2.5$ s (i.e., $\left.0.02<Q /\left(x^{2} u_{\infty}{ }^{2}\right)<0.8\right)$ indicate that both thermal and swarm conditions could be formed since more data have the normalized cloud buoyancy of smaller than 0.1 . For $t=2.5 \mathrm{~s}$, the $\mathrm{R}^{2}$ values of $w$ and $u_{f}$ were 0.6122 and 0.5904 , respectively. The $\mathrm{R}^{2}$ values of predictions indicate that the statistical model is not able to find strong correlations among the independent variables and the responses. In this particular case, the model attempts to find a correlation among the parameters from two separate flow regimes. In order to overcome the unsatisfactory performance of the statistical model, responses were selected from a narrow range of non-dimensional cloud buoyancy in turbulent thermal regime (i.e., $\left.0.36<Q /\left(x^{2} u_{\infty}{ }^{2}\right)<0.75\right)$ as mentioned earlier. Since the 
normalized cloud buoyancy varies within five orders of magnitudes (i.e., $\left.0.001<Q /\left(x^{2} u_{\infty}{ }^{2}\right)<100\right)$ the selected range of turbulent thermal from 0.36 to 0.75 in this study can be considered as a narrow range. Table 2 shows the experimental details and the related non-dimensional parameters of sand jet thermal in stagnant water for $0.36<Q /\left(x^{2} u_{\infty}{ }^{2}\right)<0.75$.

The arrangements of the four-factor five-level CCD model with the experimental response results for $w$ and $u_{f}$ are presented in Table 5. The regression analysis was performed to fit the response functions $\left(Y_{1}=w, Y_{2}=u_{f}\right)$ with the quadratic equation (Eq. (6)) as follows

$$
\begin{aligned}
Y_{1}= & 106.98-959.5 X_{1}-12.75 X_{2}+18.21 X_{3}+0.474 X_{4}-9.88 X_{1} X_{2}-22.73 X_{1} X_{3}+0.0126 X_{1} X_{4} \\
& +0.697 X_{2} X_{3}-0.016 X_{2} X_{4}-10.6 \times 10^{-3} X_{3} X_{4}+1242.33 X_{1}^{2}-0.479 X_{2}^{2}-0.562 X_{3}^{2} \\
& -65.6 \times 10^{-5} X_{4}^{2}
\end{aligned}
$$

$$
\begin{aligned}
Y_{2}= & 269.93-605.53 X_{1}-7.94 X_{2}-0.54 X_{3}+1.247 X_{4}+39.75 X_{1} X_{2}-50.2 X_{1} X_{3}+1.61 X_{1} X_{4} \\
& -0.274 X_{2} X_{3}-0.0585 X_{2} X_{4}-22.85 \times 10^{-3} X_{3} X_{4}+1291.37 X_{1}^{2}-0.652 X_{2}^{2}+1.258 X_{3}^{2} \\
& +97.93 \times 10^{-5} X_{4}^{2}
\end{aligned}
$$

The significance of the fit of the quadratic functions for experimental data was tested by means of analysis of variance (ANOVA). The outcome of ANOVA for the quadratic regression equations for the responses $Y_{1}$ and $Y_{2}$ are summarized in Tables 6 and 7, respectively. The model F-values for $Y_{1}$ and $Y_{2}$ were 18.97 and 17.87, respectively. Based on the statistical analysis (Montgomery 2012), if values of Prob $>\mathrm{F}$ are less than 0.050, the model is considered to be significant and if the values of Prob $>F$ are greater than 0.100 , the model becomes insignificant. The P-values and Prob> F are indicated for both responses in Tables 6 and 7. The significant model terms are those with the value of less than 0.05 for "Prob $>F$ " which are shown in Tables 6 and 7. This indicates that all parameters with the P-value $>0.05$ have less effect on the prediction of the dependent parameter. Base on this criterion, terms $X_{1}, X_{3}, X_{1} X_{3}, X_{1}^{2}, X_{3}^{2}$ are the significant terms in Eq. (9) and terms $X_{1}, X_{3}, X_{4}, X_{1} X_{3}, X_{1} X_{4}, X_{2} X_{4}, X_{1}^{2}, X_{3}^{2}$ are the significant terms in Eq. (10). By omitting the insignificant model terms, the models are improved and summarized as

$$
Y_{1}=106.98-959.5 X_{1}+18.21 X_{3}-22.73 X_{1} X_{3}-0.016 X_{2} X_{4}+1242.33 X_{1}^{2}-0.562 X_{3}^{2}
$$




$$
\begin{aligned}
Y_{2}= & 269.93-605.53 X_{1}-0.54 X_{3}+1.247 X_{4}-50.2 X_{1} X_{3}+1.61 X_{1} X_{4} \\
& +0.0585 X_{2} X_{4}+1291.37 X_{1}^{2}+1.258 X_{3}^{2}
\end{aligned}
$$

The $\mathrm{R}^{2}$ values of $w$ and $u_{f}$ were 0.943 and 0.940 , respectively. The high $\mathrm{R}^{2}$ values indicate the high correlations between the observed and predicted values. The high $\mathrm{R}^{2}$ values of $w$ and $u_{f}$, indicate that only $5.7 \%$, and $6 \%$ of the variability in the response parameters were not explained by the proposed statistical equations, respectively. Also, an acceptable agreement with the adjusted determination coefficient is necessary. The adjusted $\mathrm{R}^{2}$ values of $w$ and $u_{f}$ were found to be 0.893 and 0.887 , respectively. This indicates that the regression model provides an excellent explanation of the relationship between the independent variables and responses. Equations (11) and (12) can be further simplified by removing one more term from each equation. Table 7 shows that the term $X_{2} X_{4}$ has the highest $\mathrm{P}$-value amongst other remaining terms. This indicates that the nozzle size $\left(X_{2}\right)$ and the release height $\left(X_{4}\right)$ are independent and their product does not have any influence on prediction of responses. By removing the term $X_{2} X_{4}$ from Eq. (12), the error of prediction due to further simplification increased by $16 \%$ and $13 \%$ for tests 1 and 5 , respectively.

Figure 4 shows the measured and the predicted values for $w$ and $u_{f}$. As can be seen in Figure 4a, the statistical model adequately predicted the cloud width $w$ within a maximum $\pm 20 \%$ variation. More scatter was found for the prediction of cloud width particularly for small cloud width $(w<60 \mathrm{~mm})$. Part of the prediction errors for the cloud width may due to the uncertainty of the width measurements (i.e., $\pm 6.5 \%$ ). Predictions of the frontal velocity of the cloud with the RSM method were within $\pm 20 \%$ as well. Similarly, the uncertainties of velocity measurements in turbulent thermal regime were high (i.e., $\pm 6 \%$ ). The normal percentage probability and studentized residual plots for model responses are presented in Figure 5. The normal probability is an important tool to assess if the errors are normally distributed and if the error variance is homogenous. The data points indicate that neither response transformation was required nor there was any apparent problem with normality. The evaluations of normal probability show that the developed sets of equations provided a convincingly good estimate of the responses in the studied ranges of the variables. 
Three-dimensional (3D) response surfaces are presented as a function of two variables at a time, maintaining other variables at the fixed levels. The 3D response surface plots for the measured responses ( $w$ and $u_{f}$ ) were constructed based on the quadratic Eqs. (8) and (9), respectively. The effects of the four different variables of $D_{50}, d_{o}, m$, and $h$ and their interactions on the responses were visualized in the 3D response surface plots in Figures 6 and 7.

Figure 6 shows the 3D response surface to study the effects of the independent parameters on the cloud width $w$. Sand particle size $D_{50}$ was found to be the dominant parameter in controlling the width of the cloud as shown in Figures $6 a, 6 b$, and $6 \mathrm{c}$. Effect of sand particle size on the cloud width can be explained trough the energy transfer between particles and ambient stagnant water. The energy transfer can be characterized by particle relaxation time $\tau_{p}=\left(\rho_{p} D_{50}{ }^{2}\right) / 18 \mu$ (Wang et al. 2009; Muste et al. 1998) and it can be normalized with the initial characteristic time of the fluid $\left(\tau_{f}=d_{o} / u_{o}\right)$ to form the initial Stokes number $S_{\text {to }}$ as follows

$$
\mathrm{S}_{\mathrm{to}}=\frac{\tau_{p}}{\tau_{f}}=\frac{\rho_{p} D_{50}^{2} u_{o}}{18 \mu d_{o}}
$$

The extent to which the particles follow the vortex motion and turbulent eddies of the ambient water can be estimated with the initial Stokes number. Table 2 shows the Stokes numbers calculated in all tests ranging from 0.05 to 0.94 . The initial Stokes number is small for small particle size and small initial velocity. As can be seen in Table 2, the initial Stokes numbers for small particle sizes of $D_{50}=0.1375 \mathrm{~mm}$ and $0.196 \mathrm{~mm}$ are 0.05 and 0.09 , respectively. In this case, all particles follow the vortex motion and turbulent eddies whereas for a cloud with large particle sizes and high initial velocity, particles break the vortex and fall down straightly. The initial Stokes number for $D_{50}=0.595 \mathrm{~mm}$ is 0.94 as presented in Table 2. Eq. (13) shows that the Stokes number increases with the square of particle size (i.e., $\mathrm{S}_{\mathrm{to}} \sim D_{50}{ }^{2}$ ). This indicates that small particles (small $S_{t o}$ ) tend to follow the vortex motion whereas large particles break the vortices and tend to fall down without particle dispersion. This phenomenon was clearly demonstrated in the 3D surface plots (see Figures $6 \mathrm{a}, 6 \mathrm{~b}$, and $6 \mathrm{c}$ ). These figures show that the cloud width increased significantly with the decreasing of the particle size.

Variation of the cloud width $w$ with nozzle diameter $d_{o}$ was found to be very minor as indicated in Figures 6a, 6d, and 6e. The initial particle velocity was estimated by Azimi et al. (2012a) as 
$u_{o}=0.6\left(g d_{o}\right)^{1 / 2}$. Substituting the expression for the initial velocity into the Eq. (13) shows that the initial Stokes number is inversely proportional to the square root of nozzle diameter (i.e. $S_{\text {to }} \sim$ $d_{o}^{-1 / 2}$ ). Figure 6 a shows that changing the nozzle diameter from $5 \mathrm{~mm}$ to $14 \mathrm{~mm}$ slightly increased the cloud width if all other parameters kept unchanged.

The interactions between particle size $D_{50}$ and particle mass $m$ and their effects on cloud width $w$ are shown in Figure 6b. This figure shows that for the small particle size $\left(D_{50}=0.1375 \mathrm{~mm}\right)$, increasing the mass of particles increases the cloud width. The growth of the particle cloud for small particles $\left(D_{50}=0.1375 \mathrm{~mm}\right)$ can be due to the higher turbulent dispersion of small particles (Crowe 2000). A peak in the cloud width was found for $D_{50}=0.595 \mathrm{~mm}$ and $m=10 \mathrm{~g}$ (Figure 6b). The peaks in the 3D response surface plots justify the existence of an optimal solution for the mixing of sand particles in ambient water.

Sand particle clouds with large particle sizes and small particle masses form small nondimensional cloud buoyancy (see Eq. (3)). For example, the non-dimensional cloud buoyancy becomes much smaller than 0.1 for the larger particles $\left(D_{50}=0.595 \mathrm{~mm}\right)$ and smaller cumulative sand masses $(m<10 \mathrm{~g})$. These types of particle clouds turn into swarm regime very quickly. Therefore, for such cases, the turbulent thermal regime occurs in a very short time after the release of sand particles in water and particle clouds quickly enter the swarm regime. This explains the small values of $w$ for tests with large particle size and small sand masses. Figure $6 \mathrm{~b}$ also shows that increasing the mass of particles increased the cloud width to a certain extent. For tests with large particle mass $(m=18 \mathrm{~g})$ and large particle size $\left(D_{50}=0.595 \mathrm{~mm}\right)$, the cloud width decreased due to the generation of wake behind the frontal particles. Wake formation helping particles to break down the generated water vortices and fall down straightly. This behaviour resulted in declining the cloud width after the peak had passed as shown in Figure 6b.

As it is expected, higher release height of particles $h$ increases the initial velocity of particles and considerably changes the dynamics of particle clouds. This result is justified by this fact that the excess potential energy of sand particles was comparable with the rate of energy dissipation once particles hit the water surface. The excess kinetic energy due to the extra release height was dissipated through a series of surface waves at the air-water interface. The $3 \mathrm{D}$ response surface presented by Figure $6 \mathrm{f}$ displays that the release height $h$ slightly decreased the cloud width for 
the large mass of particles however not a strong correlations were noticed between $h$ and $d_{o}$ and $h$ and $D_{50}$ in the range of variables being tested.

Effects of the independent parameters on variations of frontal velocities of particle clouds are presented in Figure 7. Particle size was found to be the most significant variable in controlling frontal velocity. As can be seen in Figures 7a, 7b, and 7c, $u_{f}$ increases with increasing particle size $D_{50}$ except for the large masses of particles (Figure $7 \mathrm{~b}$ ). Figure $7 \mathrm{~b}$ shows that a minimum frontal velocity was found for the largest particle masses $(m=18 \mathrm{~g})$ and for the particle size of $\left(D_{50} \approx 0.35 \mathrm{~mm}\right)$. As can be seen from Figure $7 \mathrm{c}$, the effect of release height was dominant for test with larger particle sizes. In this condition, frontal velocity $u_{f}$ increased by increasing the release height. This behaviour can be explained by employing the conservation of energy. The release height increases the potential energy of the system and a portion of this added energy transfers into kinetic energy and increases the frontal velocity of particle cloud.

\section{Summary and Conclusions}

Effects of four controlling parameters (i.e., $D_{50}, d_{o}, m$, and $h$ ) on the dynamics of particle clouds in stagnant water were investigated using dimensional analysis and response surface methodology (RSM). Performance of RSM model was compared with the Azimi's empirical correlation to predict the frontal velocity of sand jets. It was found that the RSM model was able to predict the trend properly by showing non-linear velocity drop with the axial distance from the nozzle. However, the RSM model was not able to provide accurate prediction of frontal velocity close to the nozzle for $x / d_{o}<10$.

Three-dimensional response surfaces were plotted to show the effect of two variables at a time on the model responses while other variables maintained at the centered levels. It was found that particle size plays a significant role in variations of $w$ and $u_{f}$. Effects of independent variables on particle cloud were explained through particle-vortex interactions. It was deduced that the cloud width increased significantly with decreasing particle size since small particles tend to follow the vortex motion and this increased the cloud width. On the other hand, large particles break the vortices and tend to fall down without particle dispersion. A peak in the cloud width was found for large particle size $\left(D_{50}=0.595 \mathrm{~mm}\right)$ and $m=10 \mathrm{~g}$. A minimum frontal velocity was found for large masses of sand particles $(m=18 \mathrm{~g})$ and for particle size of $\left(D_{50} \approx 0.35 \mathrm{~mm}\right)$. Effect of release 
height on frontal velocity of particle cloud was also studied. Release height was found to be dominant parameter for large particle sizes. It was found that the frontal velocity increased with increasing the release height.

\section{Acknowledgment}

The authors are thankful to undergraduate students (Jasdeep Dhillon, Yi-Change Lee, Guillermo Martinez, and Benjamin Pomphrey) for their help with the laboratory measurements as part of their undergraduate degree project. 


\section{Nomenclature}

The following symbols are used in this paper:

$c_{o}=$ sand volumetric concentration, $\mathrm{vol} / \mathrm{vol}$

$d_{o}=$ nozzle diameter, $\mathrm{mm}$

$D_{50}=$ sand diameters at which $50 \%$ of the sand particles present are finer, $\mathrm{mm}$

$\mathrm{F}=$ densimetric Froude number

$g=$ acceleration due to gravity, $\mathrm{m} / \mathrm{s}^{2}$

$h=$ release height, $\mathrm{mm}$

$k=$ number of studied factors in Eq. (6)

$m=$ particle mass, $\mathrm{g}$

$Q=$ cloud buoyancy, $\mathrm{m}^{4} / \mathrm{s}^{2}$

$\mathrm{R}^{2}=$ coefficient of correlation

$\mathrm{R}=$ Reynolds number

$\operatorname{Re}_{\mathrm{p}}=$ particle Reynolds number

$\mathrm{S}_{\mathrm{to}}=$ Stokes number

$t=$ time, $\mathrm{s}$

$u_{f}=$ frontal velocity of the particle cloud, $\mathrm{mm} / \mathrm{s}$

$u_{o}=$ initial velocity of sand particles, $\mathrm{mm} / \mathrm{s}$

$u_{\infty}=$ settling velocity of particle, $\mathrm{mm} / \mathrm{s}$

$V_{o}=$ initial volume, $\mathrm{mm}^{3}$

$w=$ width of particle cloud, $\mathrm{mm}$

$x=$ vertical distance from the nozzle, $\mathrm{mm}$

$X=$ independent variable

$Y=$ response

$\beta=$ coefficient in Eq. (6)

$\mu=$ dynamic viscosity,

$\rho_{s}=$ density of sand, $\mathrm{kg} / \mathrm{m}^{3}$

$\rho_{w}=$ density of water, $\mathrm{kg} / \mathrm{m}^{3}$

$\tau_{p}=$ particle relaxation time, $\mathrm{s}$

$\tau_{f}=$ characteristic time, $\mathrm{s}$ 


\section{References}

Azimi, A. H., Zhu, D. Z., and Rajaratnam, N. 2011. Effect of particle size on the characteristics of sand jet in water. Journal of Engineering Mechanics, ASCE, Vol. 137(12), pp. 822-834.

Azimi, A. H., Zhu, D. Z., and Rajaratnam, N. 2012a. Experimental study of sand jet front in water. Int. J. Multiphase Flow, Vol. 40, pp. 19-37.

Azimi, A. H., Zhu, D. Z., Rajaratnam, N. 2012b. Computational investigation on vertical slurry jets. Int. J. Multiphase Flow. Vol. 47, pp. 94-114.

Azimi, A. H., Zhu, D. Z., and Rajaratnam, N. 2014. Experimental study of subaqueous sand deposition from slurry wall jets. Journal of Engineering Mechanics, Vol. 140(2), pp. 296-314.

Batchelor, G. K. 1954. Heat convection and buoyancy effects in fluids. Q. J. R. Meteorol. Soc. 80, 339-358.

Box, G. E. P., and Wilson, K. B. 1951. On the experimental attainment of optimum conditions (with discussion). Journal of the Royal Statistical Society Series, B13 (1) pp.1-45.

Box, G. E. P., and Behnken, D. 1960. Some new three level designs for the study of quantitative variables. Technometrics 2, pp. 455-475. 
Buhler, J., and Papantoniou, D. 2001. On the motion of suspension thermals and particle swarms J. Hydrul. Res., 39 (6), 643-653.

Bush, J. W. M., Thurber, B. A., and Blanchette, F. 2003. Particle clouds in homogeneous and stratified environments. J. Fluid Mech., Vol. 489, pp. 29-54.

Crowe C. T. 2000. On models for turbulence modulation in fluid-particle flows. Int. J. Multiphase Flow, Vol. 26, pp. 719-727.

Deng, L., and Cai, C. S. 2010. Bridge model updating using response surface method and genetic algorithm. Journal of Bridge Engineering, ASCE, Vol. 15(5), pp. 553-564.

Dietrich, W. 1982. Settling velocity of natural particles, Water Resources Res., 18, 1615-1626.

Fischer, H.B., List, E.J., Koh, R.C.Y., Imberger, J., Brooks, N.H. 1979. Mixing in Inland and Coastal Waters. Academic press, San Diego, California, USA, 483p.

Ghafoori, S., Mehrvar, M., and Chan, P. 2014. Optimisation of photo-Fenton-like degradation of aqueous ployacrylic acid using Box-Behnken experimental design. The Canadian Journal of Chemical Engineering, Vol. 92, pp. 97-108.

Gore, R. A., Crowe, C.T. 1989. Effect of particle size on modulating turbulent intensity. Int. J. Multiphase Flow, Vol. 15, pp. 279-285. 
Haghshenas, H. F., Khodaii, A., Mehrara, A., Dehnad, M. H., and Ahari, A. S. 2014. Frequency and temperature interactive effects on hot mix permanent deformation using response surface methodology. Journal of Materials in Civil Engineering, ASCE, Vol. 26 (6), 06014003.

Holdich, R.G., 2002. Fundamentals of particle technology. Midland Inform. Technol. Publ., 173 p.

Kirmizakis, P., Tsamoutsoglou, C., Kayan, B. and Kalderis, D. 2014. Subcritical water treatment of landfill leachate: Application of response surface methodology. Journal of Environmental Management, Vol. 146, pp. 9-15.

Lai, A. C. H., Zhao, B., Law A. W. K., and Adams, E. E. 2013. Two-phase modeling of sediment clouds. Environ Fluid Mech., 13, 435-463.

Lai, A. C. H., Zhao, B., Law A. W. K., and Adams, E. E. 2015. A numerical and analytical study of the effect of aspect ratio on the behaviour of a round thermal. Environ Fluid Mech., 15, 85108.

Lai, A. C. H., Wang, R., Law A. W. K., and Adams, E. E. 2016a. Modeling and experiments of polydisperse particle clouds. Environ Fluid Mech., 16, 875-898. 
Lai, A. C. H., Chan, S. N., Law A. W. K., and Adams, E. E. (2016b). Spreading hypothesis of a particle plume. ASCE, J. Hydraul. Eng., 04016065-1-12.

Mollon, G., Dias, D., and Soubra, A. 2009. Probabilistic analysis of circular tunnels in homogenous soil using response surface methodology. Journal of Geotechnical and Geoenvironmental Engineering, ASCE, Vol. 135(9), pp. 1314-1325.

Montgomery, D. C. 2012. Design and analysis of experiments. $8^{\text {th }}$ Edition, John Wiley \& Sons, New York, 730 p.

Morton, B. R., Taylor, G., Turner, J. S. 1956. Turbulent gravitational convection from maintained and instantaneous sources. Proc. R. Soc. Lond. Ser. A, Math. Phys. Sci. 234, 1-23.

Muste, M., Fujita, I., Kruger, A. 1998. Experimental comparison of two laser-based velocimeters for flows with alluvial sand. Exp. Fluids, Vol. 24, pp. 273-284.

Myers, R. H., and D. C. Montgomery, D. C. 2002. Response Surface Methodology: Process and Product Optimisation Using Designed Experiment., $2^{\text {nd }}$ Edition. John Wiley and Sons, New York, pp. 13-55.

Noh, Y., and Fernando, H. J. S. 1993. The transition in the sedimentation pattern of a particle cloud. Phys. Fluids A, Vol. 5(12), pp. 3049-3055. 
Pakzad, L., Ein-Mozaffari, F., Upreti, S. R., and Lohi, A. 2013. Evaluation of the mixing of nonNewtonian biopolymer solutions in the reactors equipped with the coaxial mixers through tomography and CFD. Chemical Engineering Journal, 215-216, pp. 279-296.

Wang, B., Zhang, H., Liu, Y. Yan, X., and Wang, X. 2009. Particle modulations to turbulence in two-phase round jets. Acta Mech. Sinica, Vol. 25, pp. 611-617.

Wang, R., Wing-Keung Law, A., and Adams, E. E. 2014. Large-eddy simulation (LES) of settling particle cloud dynamics. Int. J. Multiphase Flow, 67, 65-75.

Wang, R., Adams, E. E., Law, A. W. K., and Lai, A. C. H. 2015. Scaling particle cloud dynamics: from lab to field. ASCE, J. Hydraul. Eng., 141 (7), 1-4.

Yahyapour, S., Golshan, A., and Ghazali, A. H. B. 2014. Removal of total suspended solids and turbidity within experimental vegetated channel: optimization through response surface methodology. Journal of Hydro-environment Research, Vol. 8, pp. 260-269.

Zhao, B., Law, A. W. K., Adams, E. E., Shao, D., and Huang, Z. 2012. Effect of air release height on the formation of sediment thermals in water. J. Hydraulic Research, 50 (2), 532-540.

Zhao, B., Law, A. W. K., Adams, E. E., and Er, J. W. 2014. Formation of particle clouds. J. Fluid Mech., Vol. 746, 193-213. 
Table 1: Experimental range and levels of the independent variables based on central composite design (CCD) for the present experimental tests.

\begin{tabular}{|c|c|c|c|c|c|c|}
\hline \multirow{2}{*}{$\begin{array}{l}\text { Independent } \\
\text { variables }\end{array}$} & \multirow{2}{*}{ Symbols } & \multicolumn{5}{|c|}{ Coded levels } \\
\hline & & -2 & -1 & 0 & 1 & 2 \\
\hline $\begin{array}{c}D_{50} \\
(\mathrm{~mm}) \\
\end{array}$ & $X_{1}$ & 0.1375 & 0.196 & 0.389 & 0.507 & 0.595 \\
\hline $\begin{array}{c}d_{o} \\
(\mathrm{~mm})\end{array}$ & $X_{2}$ & 6 & 8 & 10 & 12 & 14 \\
\hline $\begin{array}{l}m \\
(g) \\
\end{array}$ & $X_{3}$ & 1 & 3 & 6 & 12 & 18 \\
\hline $\begin{array}{c}h \\
(\mathrm{~mm})\end{array}$ & $X_{4}$ & 0 & 100 & 200 & 300 & 400 \\
\hline
\end{tabular}


Table 2: Experimental details and the related non-dimensional parameters of sand jet thermal in stagnant water.

\begin{tabular}{|c|c|c|c|c|c|c|c|c|c|c|c|}
\hline \multirow[b]{2}{*}{$\begin{array}{l}\text { Test } \\
\text { No. }\end{array}$} & \multicolumn{4}{|c|}{ Independent variables } & \multirow[b]{2}{*}{$\begin{array}{c}u_{o} \\
(\mathrm{~mm} / \mathrm{s})\end{array}$} & \multirow[b]{2}{*}{$\begin{array}{c}u_{\infty} \\
(\mathrm{mm} / \mathrm{s})\end{array}$} & \multirow[b]{2}{*}{$\mathrm{R}$} & \multirow[b]{2}{*}{$\mathrm{Re}_{\mathrm{p}}$} & \multirow[b]{2}{*}{$\mathrm{F}$} & \multirow[b]{2}{*}{$S_{\text {to }}$} & \multirow[b]{2}{*}{$\frac{Q}{\left(x^{2} u_{\infty}^{2}\right)}$} \\
\hline & $\begin{array}{c}D_{50} \\
(\mathrm{~mm})\end{array}$ & $\begin{array}{c}d_{o} \\
(\mathrm{~mm})\end{array}$ & $\begin{array}{c}h \\
(\mathrm{~mm})\end{array}$ & $\begin{array}{l}m \\
(g)\end{array}$ & & & & & & & \\
\hline 1 & 0.196 & 8 & 100 & 3 & 168 & 22 & 1344 & 4.31 & 3.09 & 0.11 & 0.56 \\
\hline 2 & 0.507 & 8 & 100 & 3 & 168 & 74 & 1344 & 37.52 & 1.92 & 0.76 & 0.43 \\
\hline 3 & 0.196 & 12 & 100 & 3 & 206 & 22 & 2472 & 4.31 & 3.79 & 0.09 & 0.59 \\
\hline 4 & 0.507 & 12 & 100 & 3 & 206 & 74 & 2472 & 37.52 & 2.35 & 0.62 & 0.66 \\
\hline 5 & 0.196 & 8 & 100 & 12 & 168 & 22 & 1344 & 4.31 & 3.09 & 0.11 & 0.53 \\
\hline 6 & 0.507 & 8 & 100 & 12 & 168 & 74 & 1344 & 37.52 & 1.92 & 0.76 & 0.52 \\
\hline 7 & 0.196 & 12 & 100 & 12 & 206 & 22 & 2472 & 4.31 & 3.79 & 0.09 & 0.54 \\
\hline 8 & 0.507 & 12 & 100 & 12 & 206 & 74 & 2472 & 37.52 & 2.35 & 0.62 & 0.63 \\
\hline 9 & 0.196 & 8 & 300 & 3 & 168 & 22 & 1344 & 4.31 & 3.09 & 0.11 & 0.52 \\
\hline 10 & 0.507 & 8 & 300 & 3 & 168 & 74 & 1344 & 37.52 & 1.92 & 0.76 & 0.48 \\
\hline 11 & 0.196 & 12 & 300 & 3 & 206 & 22 & 2472 & 4.31 & 3.79 & 0.09 & 0.63 \\
\hline 12 & 0.507 & 12 & 300 & 3 & 206 & 74 & 2472 & 37.52 & 2.35 & 0.62 & 0.75 \\
\hline 13 & 0.196 & 8 & 300 & 12 & 168 & 22 & 1344 & 4.31 & 3.09 & 0.11 & 0.67 \\
\hline
\end{tabular}




\begin{tabular}{|c|c|c|c|c|c|c|c|c|c|c|c|}
\hline 14 & 0.507 & 8 & 300 & 12 & 168 & 74 & 1344 & 37.52 & 1.92 & 0.76 & 0.74 \\
\hline 15 & 0.196 & 12 & 300 & 12 & 206 & 22 & 2472 & 4.31 & 3.79 & 0.09 & 0.64 \\
\hline 16 & 0.507 & 12 & 300 & 12 & 206 & 74 & 2472 & 37.52 & 2.35 & 0.62 & 0.58 \\
\hline 17 & 0.138 & 10 & 200 & 6 & 188 & 13 & 1880 & 1.79 & 4.12 & 0.05 & 0.71 \\
\hline 18 & 0.595 & 10 & 200 & 6 & 188 & 88 & 1880 & 52.36 & 1.98 & 0.94 & 0.36 \\
\hline 19 & 0.389 & 6 & 200 & 6 & 146 & 55 & 876 & 21.40 & 1.90 & 0.52 & 0.42 \\
\hline 20 & 0.389 & 14 & 200 & 6 & 222 & 55 & 3108 & 21.40 & 2.90 & 0.34 & 0.59 \\
\hline 21 & 0.389 & 10 & 200 & 1 & 188 & 55 & 1880 & 21.40 & 2.45 & 0.40 & 0.6 \\
\hline 22 & 0.389 & 10 & 200 & 18 & 188 & 55 & 1880 & 21.40 & 2.45 & 0.40 & 0.67 \\
\hline 23 & 0.389 & 10 & 0 & 6 & 188 & 55 & 1880 & 21.40 & 2.45 & 0.40 & 0.44 \\
\hline 24 & 0.389 & 10 & 400 & 6 & 188 & 55 & 1880 & 21.40 & 2.45 & 0.40 & 0.45 \\
\hline 25 & 0.389 & 10 & 200 & 6 & 188 & 55 & 1880 & 21.40 & 2.45 & 0.40 & 0.41 \\
\hline
\end{tabular}

Table 3: Experimental range and levels of the independent variables based on central composite design (CCD) for RSM validation and modeling of sand jet front in water.

\begin{tabular}{|c|c|c|c|c|c|c|}
\hline Independent & \multirow{2}{*}{ Symbols } & \multicolumn{5}{|c|}{ Coded levels } \\
\cline { 3 - 7 } variables & -2 & -1 & 0 & 1 & 2 \\
\hline $\begin{array}{c}d_{o} \\
(\mathrm{~mm})\end{array}$ & $X_{1}$ & 2 & 3 & 4 & 4.75 & 10 \\
\hline $\begin{array}{c}X \\
\mathrm{~mm})\end{array}$ & $X_{2}$ & 50 & 150 & 250 & 500 & 750 \\
\hline
\end{tabular}


Table 4: Related non-dimensional parameters of sand jet front with the particle size of $D_{50}=0.206 \mathrm{~mm}$ from the experimental study of Azimi et al. (2012a) for model evaluation.

\begin{tabular}{|c|c|c|c|c|c|c|c|c|}
\hline $\begin{array}{c}\text { Test } \\
\text { No. }\end{array}$ & $\begin{array}{c}d_{o} \\
(\mathrm{~mm})\end{array}$ & $\begin{array}{c}x \\
(\mathrm{~mm})\end{array}$ & $x / d_{o}$ & $\begin{array}{c}u_{f} \\
(\mathrm{~mm} / \mathrm{s})\end{array}$ & $\mathrm{R}$ & $\mathrm{Re}_{\mathrm{p}}$ & $\mathrm{F}$ & $\mathrm{S}_{\text {to }}$ \\
\hline 1 & 3 & 150 & 50 & 188 & 243 & 5.20 & 2.03 & 0.17 \\
\hline 2 & 4.75 & 150 & 31.6 & 248.2 & 605 & 5.20 & 2.56 & 0.16 \\
\hline 3 & 3 & 500 & 166.7 & 142.1 & 243 & 5.20 & 2.03 & 0.17 \\
\hline 4 & 4.75 & 500 & 105.3 & 183.5 & 605 & 5.20 & 2.56 & 0.16 \\
\hline 5 & 2 & 250 & 125 & 133.9 & 144 & 5.20 & 1.58 & 0.22 \\
\hline 6 & 10 & 250 & 25 & 350.9 & 1914 & 5.20 & 4.62 & 0.11 \\
\hline 7 & 4 & 50 & 12.5 & 275.4 & 425 & 5.20 & 2.35 & 0.15 \\
\hline 8 & 4 & 750 & 187.5 & 147.3 & 425 & 5.20 & 2.35 & 0.15 \\
\hline 9 & 4 & 250 & 62.5 & 199.3 & 425 & 5.20 & 2.35 & 0.15 \\
\hline
\end{tabular}


Table 5: Four-factor, five-level CCD for RSM, along with the observed responses for the nondimensional buoyancy force range of $0.36<Q /\left(x^{2} u_{\infty}{ }^{2}\right)<0.75$.

\begin{tabular}{|c|c|c|c|c|c|c|}
\hline \multirow{3}{*}{$\begin{array}{c}\text { Test } \\
\text { No. }\end{array}$} & \multicolumn{2}{|c|}{ Independent Coded variables } & \multicolumn{2}{c|}{ Responses } \\
\cline { 2 - 7 }$(\mathrm{mm})$ & $\begin{array}{c}d_{o} \\
(\mathrm{~mm})\end{array}$ & $\begin{array}{c}m \\
(\mathrm{~g})\end{array}$ & $\begin{array}{c}h \\
(\mathrm{~mm})\end{array}$ & $\begin{array}{c}w \\
(\mathrm{~mm})\end{array}$ & $\begin{array}{c}u_{f} \\
(\mathrm{~mm} / \mathrm{s})\end{array}$ \\
\hline 1 & -1 & -1 & -1 & -1 & 93 & 74 \\
\hline 2 & 1 & -1 & -1 & -1 & 42 & 275 \\
\hline 3 & -1 & 1 & -1 & -1 & 80 & 93 \\
\hline 4 & 1 & 1 & -1 & -1 & 30 & 250 \\
\hline 5 & -1 & -1 & 1 & -1 & 184 & 99 \\
\hline 6 & 1 & -1 & 1 & -1 & 31 & 190 \\
\hline 7 & -1 & 1 & 1 & -1 & 227 & 60 \\
\hline 8 & 1 & 1 & 1 & -1 & 78 & 206 \\
\hline 9 & -1 & -1 & -1 & 1 & 90 & 61 \\
\hline 10 & 1 & -1 & -1 & 1 & 19 & 376 \\
\hline 11 & -1 & 1 & -1 & 1 & 114 & 56 \\
\hline 12 & 1 & 1 & -1 & 1 & 13 & 478 \\
\hline 13 & -1 & -1 & 1 & 1 & 169 & 89 \\
\hline 14 & 1 & -1 & 1 & 1 & 57 & 193 \\
\hline 15 & -1 & 1 & 1 & 1 & 174 & 74 \\
\hline 16 & 1 & 1 & 1 & 1 & 47 & 269 \\
\hline 17 & -2 & 0 & 0 & 0 & 236 & 30 \\
\hline
\end{tabular}




\begin{tabular}{|c|c|c|c|c|c|c|}
\hline 18 & 2 & 0 & 0 & 0 & 39 & 210 \\
\hline 19 & 0 & -2 & 0 & 0 & 70 & 143 \\
\hline 20 & 0 & 2 & 0 & 0 & 58 & 163 \\
\hline 21 & 0 & 0 & -2 & 0 & 24 & 260 \\
\hline 22 & 0 & 0 & 2 & 0 & 76 & 190 \\
\hline 23 & 0 & 0 & 0 & -2 & 37 & 189 \\
\hline 24 & 0 & 0 & 0 & 2 & 54 & 215 \\
\hline 25 & 0 & 0 & 0 & 0 & 64 & 156 \\
\hline 26 & 0 & 0 & 0 & 0 & 65 & 154 \\
\hline 27 & 0 & 0 & 0 & 0 & 63.5 & 157 \\
\hline 28 & 0 & 0 & 0 & 0 & 63.2 & 158.6 \\
\hline 29 & 0 & 0 & 0 & 0 & 66 & 152.4 \\
\hline 30 & 0 & 0 & 0 & 0 & 64.8 & 154 \\
\hline 31 & 0 & 0 & 0 & 0 & 62.8 & 160 \\
\hline
\end{tabular}

Table 6: Analysis of variance (ANOVA) regression model for response function $w . Y_{1}=106.98$ 959.5 $X_{1}-12.75 X_{2}+18.21 X_{3}+0.474 X_{4}-9.88 X_{1} X_{2}-22.73 X_{1} X_{3}+0.0126 X_{1} X_{4}+0.697 X_{2} X_{3}-0.016 X_{2} X_{4}-$ $10.6 \times 10^{-3} X_{3} X_{4}+1242.33 X_{1}^{2}-0.479 X_{2}^{2}-0.562 X_{3}^{2}-65.6 \times 10^{-5} X_{4}^{2}$.

\begin{tabular}{|c|c|c|c|c|c|}
\hline Source & $\begin{array}{c}\text { Sum of } \\
\text { squares }\end{array}$ & $\begin{array}{c}\text { Degree of } \\
\text { freedom }\end{array}$ & Mean square & F-value & $\begin{array}{c}\text { P-value, } \\
\text { Prob.>F }\end{array}$ \\
\hline Model & 95406.21 & 14 & 6814.73 & 18.97 & $<0.0001$ \\
\hline$X_{1}$ & 47589.91 & 1 & 47589.91 & 132.51 & $<0.0001$ \\
\hline$X_{2}$ & 248.10 & 1 & 248.10 & 0.69 & 0.4181 \\
\hline$X_{3}$ & 16993.88 & 1 & 16993.88 & 47.32 & $<0.0001$ \\
\hline$X_{4}$ & 153.13 & 1 & 153.13 & 0.43 & 0.5230 \\
\hline$X_{1} X_{2}$ & 154.21 & 1 & 154.21 & 0.43 & 0.5216 \\
\hline$X_{1} X_{3}$ & 4135.42 & 1 & 4135.42 & 11.51 & 0.0037 \\
\hline$X_{1} X_{4}$ & 0.63 & 1 & 0.63 & $1.762 \times 10^{-3}$ & 0.9670 \\
\hline$X_{2} X_{3}$ & 651.74 & 1 & 651.74 & 1.81 & 0.1967 \\
\hline$X_{2} X_{4}$ & 168.35 & 1 & 168.35 & 0.47 & 0.5034 \\
\hline$X_{3} X_{4}$ & 381.16 & 1 & 381.16 & 1.06 & 0.3182 \\
\hline
\end{tabular}




\begin{tabular}{|c|c|c|c|c|c|}
\hline$X_{1}^{2}$ & 6104.84 & 1 & 6104.84 & 17 & 0.0008 \\
\hline$X_{2}^{2}$ & 103.76 & 1 & 103.76 & 0.29 & 0.5983 \\
\hline$X_{3}^{2}$ & 3023.80 & 1 & 3023.80 & 8.42 & 0.0104 \\
\hline$X_{4}^{2}$ & 1211.77 & 1 & 1211.77 & 3.37 & 0.0849 \\
\hline
\end{tabular}

$\mathrm{R}^{2}=0.9432, \mathrm{R}_{\text {adj }}^{2}=0.8935, \mathrm{CV} \%=23.62$, Adequate Precision $=15.52$.

Table 7: Analysis of variance (ANOVA) regression model for response function $u_{f} . Y_{2}=269.93$ $605.53 X_{1}-7.94 X_{2}-0.54 X_{3}+1.247 X_{4}+39.75 X_{1} X_{2}-50.2 X_{1} X_{3}+1.61 X_{1} X_{4}-0.274 X_{2} X_{3}+0.0585 X_{2} X_{4^{-}}$ $22.85 \times 10^{-3} X_{3} X_{4}+1291.37 X_{1}^{2}-0.652 X_{2}^{2}+1.258 X_{3}^{2}+97.93 \times 10^{-5} X_{4}^{2}$.

\begin{tabular}{|c|c|c|c|c|c|}
\hline Source & $\begin{array}{c}\text { Sum of } \\
\text { squares }\end{array}$ & $\begin{array}{c}\text { Degree of } \\
\text { freedom }\end{array}$ & Mean square & F-value & $\begin{array}{c}\text { P-value, } \\
\text { Prob.>F }\end{array}$ \\
\hline Model & 257100 & 14 & 18366.02 & 17.87 & $<0.0001$ \\
\hline$X_{1}$ & 173100 & 1 & 173100 & 168.46 & $<0.0001$ \\
\hline$X_{2}$ & 712.60 & 1 & 712.60 & 0.69 & 0.4172 \\
\hline$X_{3}$ & 18213.01 & 1 & 18213.01 & 17.73 & 0.0007 \\
\hline$X_{4}$ & 4053.77 & 1 & 4053.77 & 3.95 & 0.0644 \\
\hline$X_{1} X_{2}$ & 2496.31 & 1 & 2496.31 & 2.43 & 0.1386 \\
\hline$X_{1} X_{3}$ & 20074.56 & 1 & 20074.56 & 19.54 & 0.0004 \\
\hline$X_{1} X_{4}$ & 10314.17 & 1 & 10314.17 & 10.04 & 0.0060 \\
\hline$X_{2} X_{3}$ & 101.04 & 1 & 101.04 & 0.098 & 0.7579 \\
\hline$X_{2} X_{4}$ & 2191.41 & 1 & 2191.41 & 2.13 & 0.1635 \\
\hline$X_{3} X_{4}$ & 1752.18 & 1 & 1752.18 & 1.71 & 0.2101 \\
\hline
\end{tabular}




\begin{tabular}{|l|c|c|c|c|c|}
\hline$X_{1}{ }^{2}$ & 6596.31 & 1 & 6596.31 & 6.42 & 0.0221 \\
\hline$X_{2}{ }^{2}$ & 192.10 & 1 & 192.10 & 0.19 & 0.6712 \\
\hline$X_{3}{ }^{2}$ & 15116.94 & 1 & 15116.94 & 14.71 & 0.0015 \\
\hline$X_{4}{ }^{2}$ & 2704.12 & 1 & 2704.12 & 2.63 & 0.1243 \\
\hline
\end{tabular}

$\mathrm{R}^{2}=0.9399, \mathrm{R}_{\mathrm{adj}}^{2}=0.8873, \mathrm{CV} \%=18.64$, Adequate Precision $=17.78$.

Figure 1: Schematic view of the experimental setup and the coordinate system.

Figure 2: Images of sand particle cloud after 3 seconds from the sand release. Nozzles were located at the water surface, $h=0 \mathrm{~mm}$ : a) Test No. 4 shows the swarm condition $\left(d_{o}=12 \mathrm{~mm}, m=\right.$ $3 \mathrm{~g}, D_{50}=0.507 \mathrm{~mm}, Q /\left(x^{2} u_{\infty}{ }^{2}\right)=0.024$, b) Test No. 5 shows the thermal condition $\left(d_{o}=8 \mathrm{~mm}, m=\right.$ $\left.12 \mathrm{~g}, D_{50}=0.196 \mathrm{~mm}, Q /\left(x^{2} u_{\infty}{ }^{2}\right)=0.580\right)$.

Figure 3: Response surface plot of the frontal velocity of particle cloud with $x$ and $d_{o}$.

Figure 4: Performance of the RSM model to predict the controlling parameters of sand jet cloud in water, a) Width of the sand jet front, $w(\mathrm{~mm}), \mathbf{b})$ Frontal velocity, $u_{f}(\mathrm{~mm} / \mathrm{s})$.

Figure 5: Normal probability plots of the internally studentized residual for the controlling parameters of sand jet cloud in water, a) Width of the sand jet front, $w(\mathrm{~mm})$, b) Frontal velocity, $u_{f}(\mathrm{~mm} / \mathrm{s})$.

Figure 6: Three-dimensional response surfaces showing the correlations of the controlling variables $\left(d_{o}, D_{50}, m, h\right)$ with the width of the sand jet cloud, $w$ : a) Interactions of $w$ with $D_{50}$ and $\left.d_{o}, \mathbf{b}\right)$ Interactions of $w$ with $D_{50}$ and $\left.m, \mathbf{c}\right)$ Interactions of $w$ with $D_{50}$ and $h, \mathbf{d}$ ) Interactions of $w$ with $d_{o}$ and $m, \mathbf{e}$ ) Interactions of $w$ with $d_{o}$ and $h$, and f) Interactions of $w$ with $m$ and $h$. 
Figure 7: Three-dimensional response surfaces showing the correlations of the controlling variables $\left(d_{o}, D_{50}, m, h\right)$ with the frontal velocity of the sand jet cloud, $u_{f}:$ a) Interactions of $u_{f}$ with $d_{o}$ and $D_{50}$, b) Interactions of $u_{f}$ with $m$ and $D_{50}$, c) Interactions of $u_{f}$ with $h$ and $D_{50}$, d) Interactions of $u_{f}$ with $m$ and $d_{o}$, e) Interactions of $u_{f}$ with $h$ and $d_{o}$, and f) Interactions of $u_{f}$ with $h$ and $m$. 


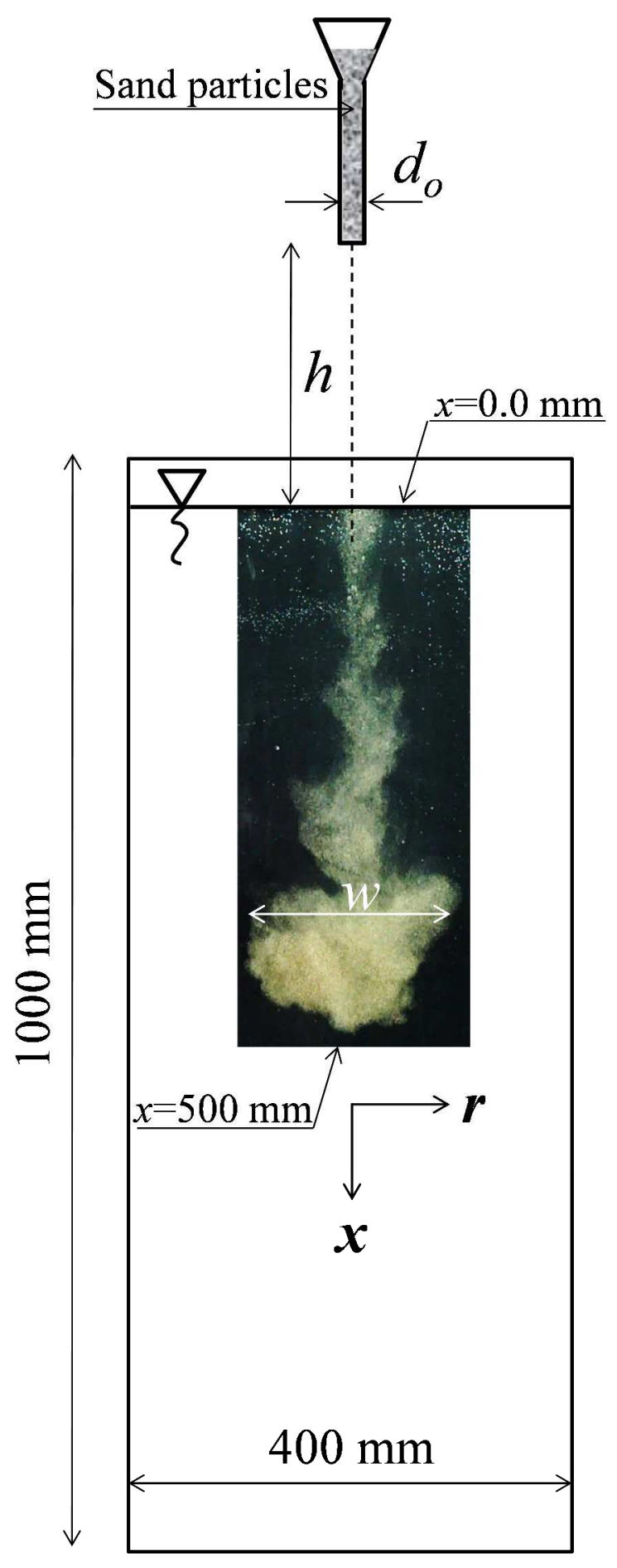



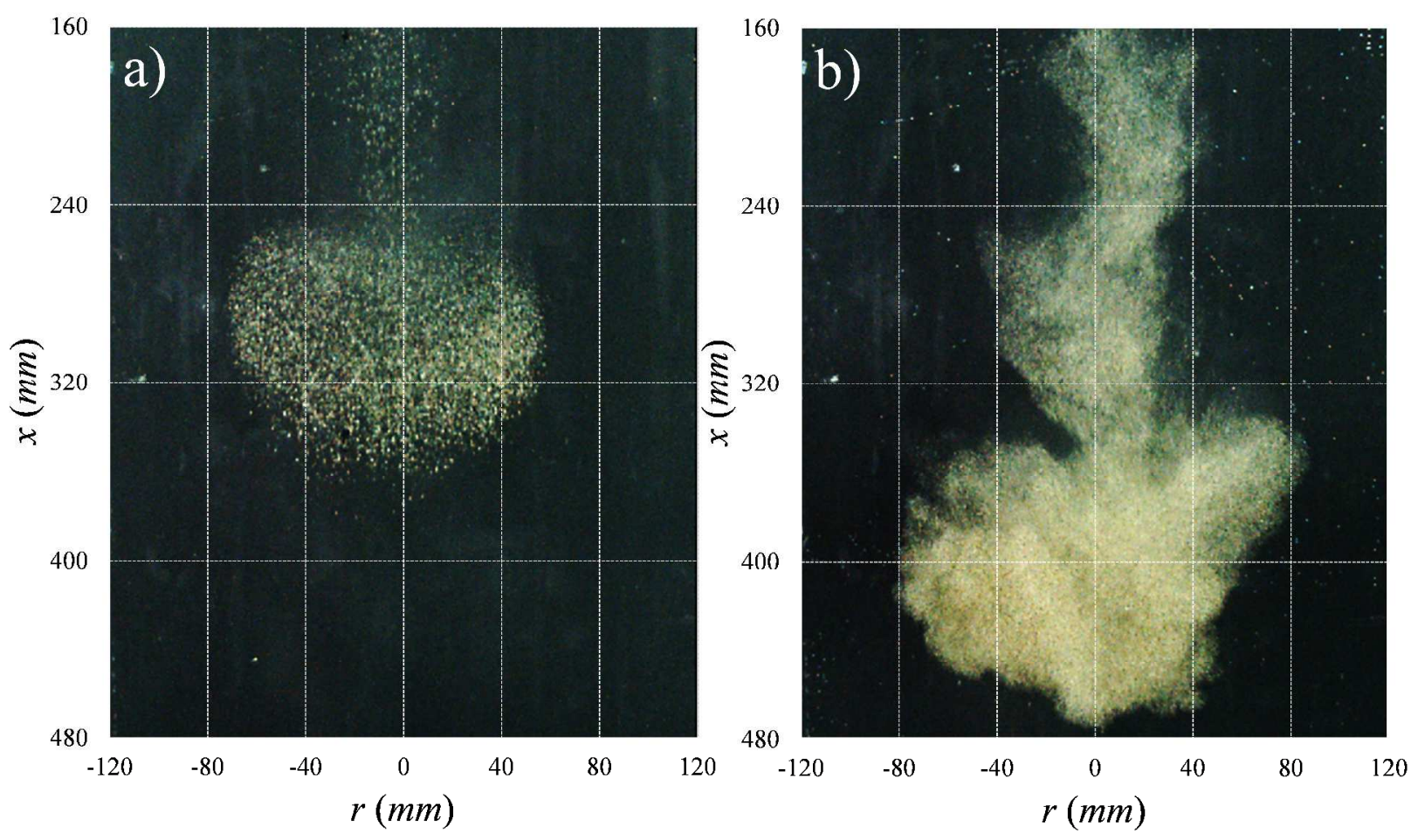


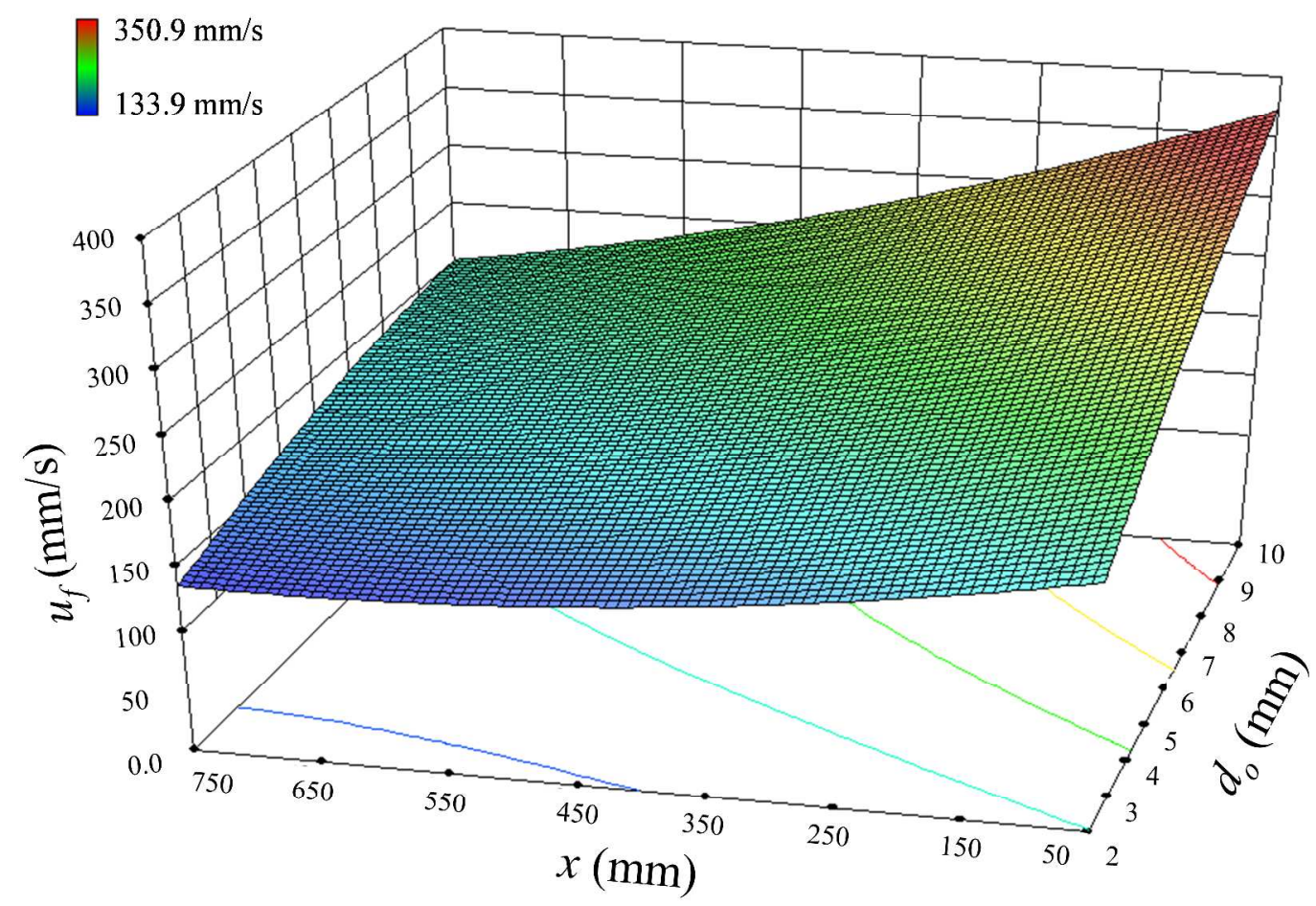



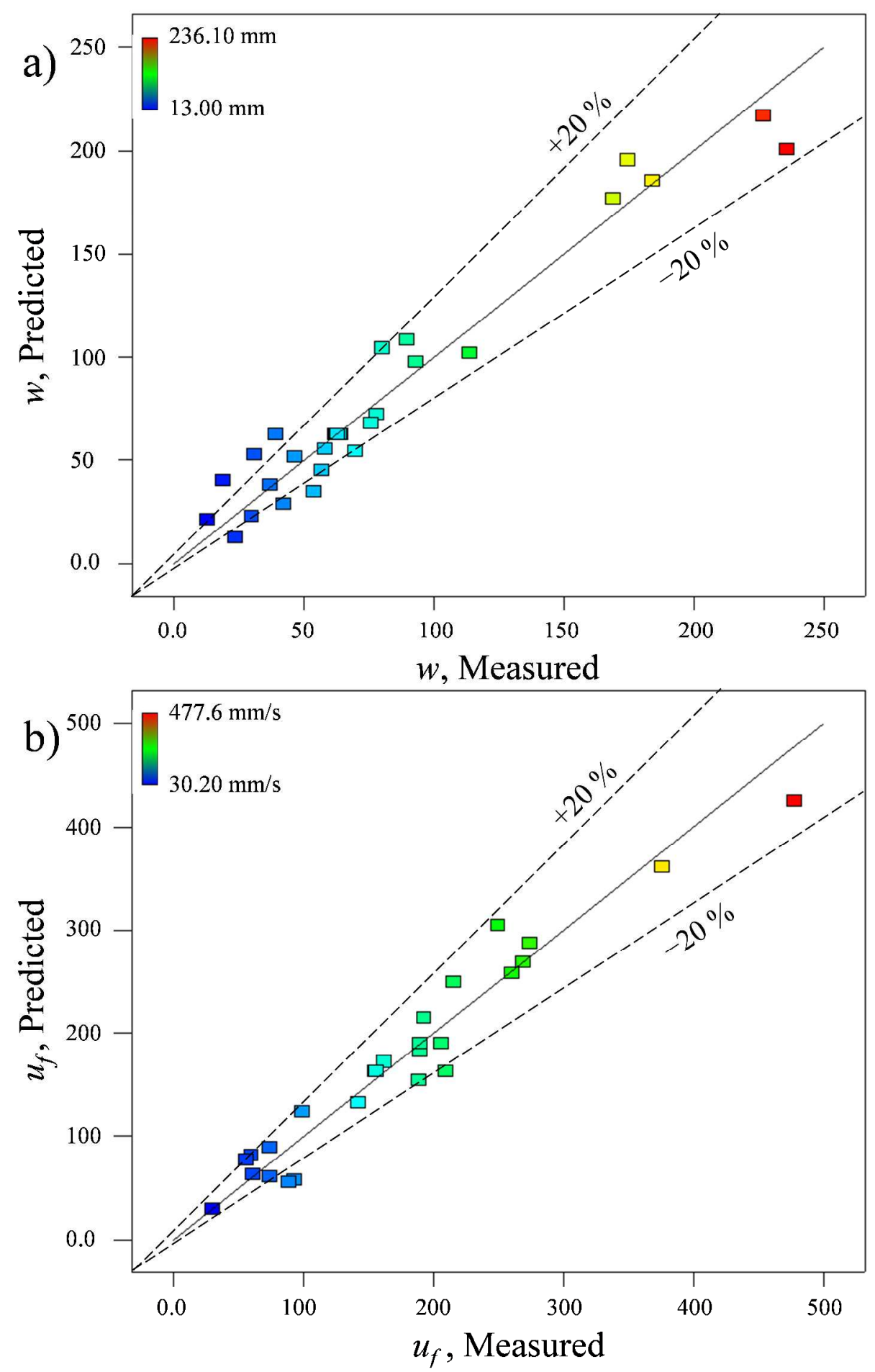

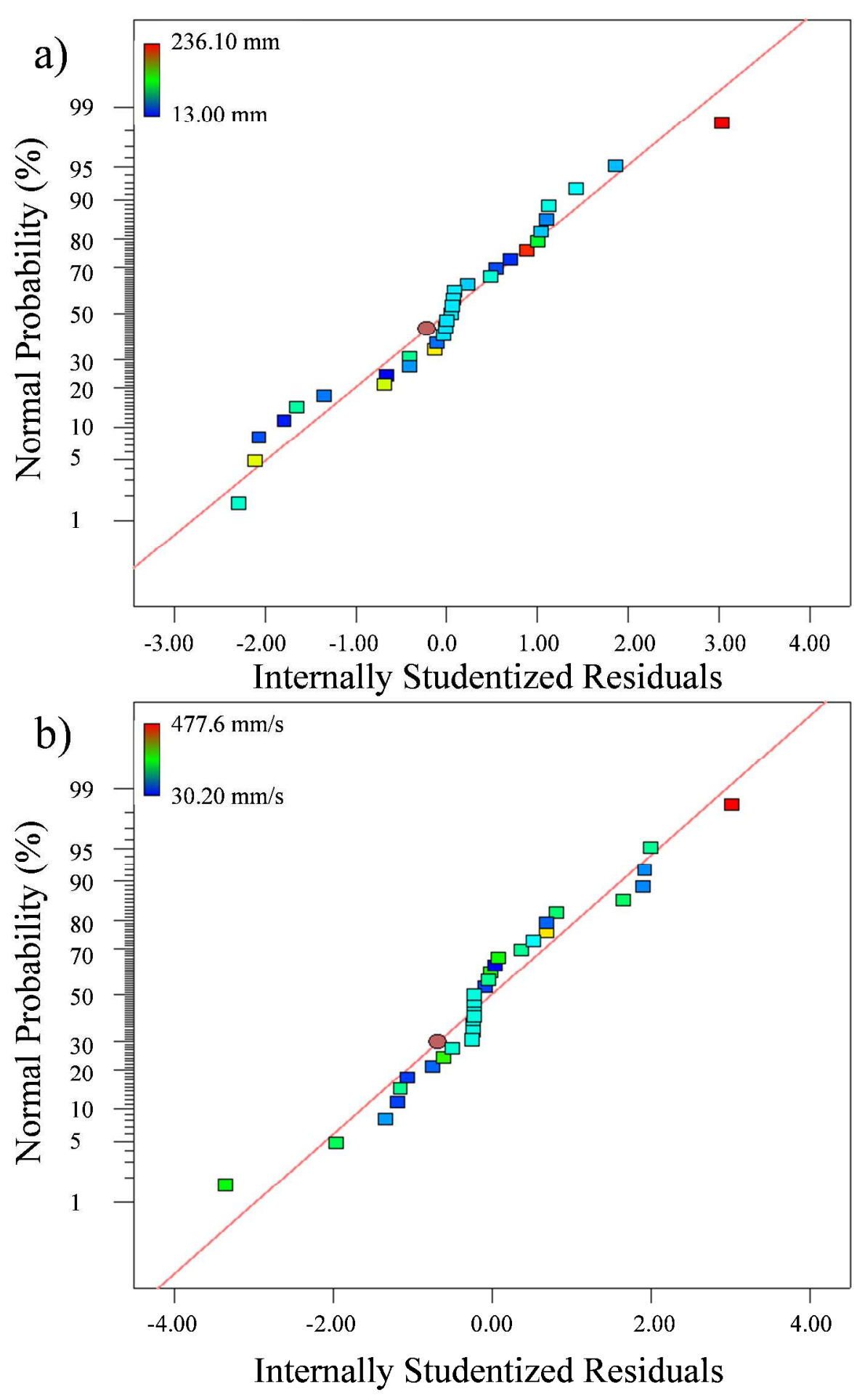

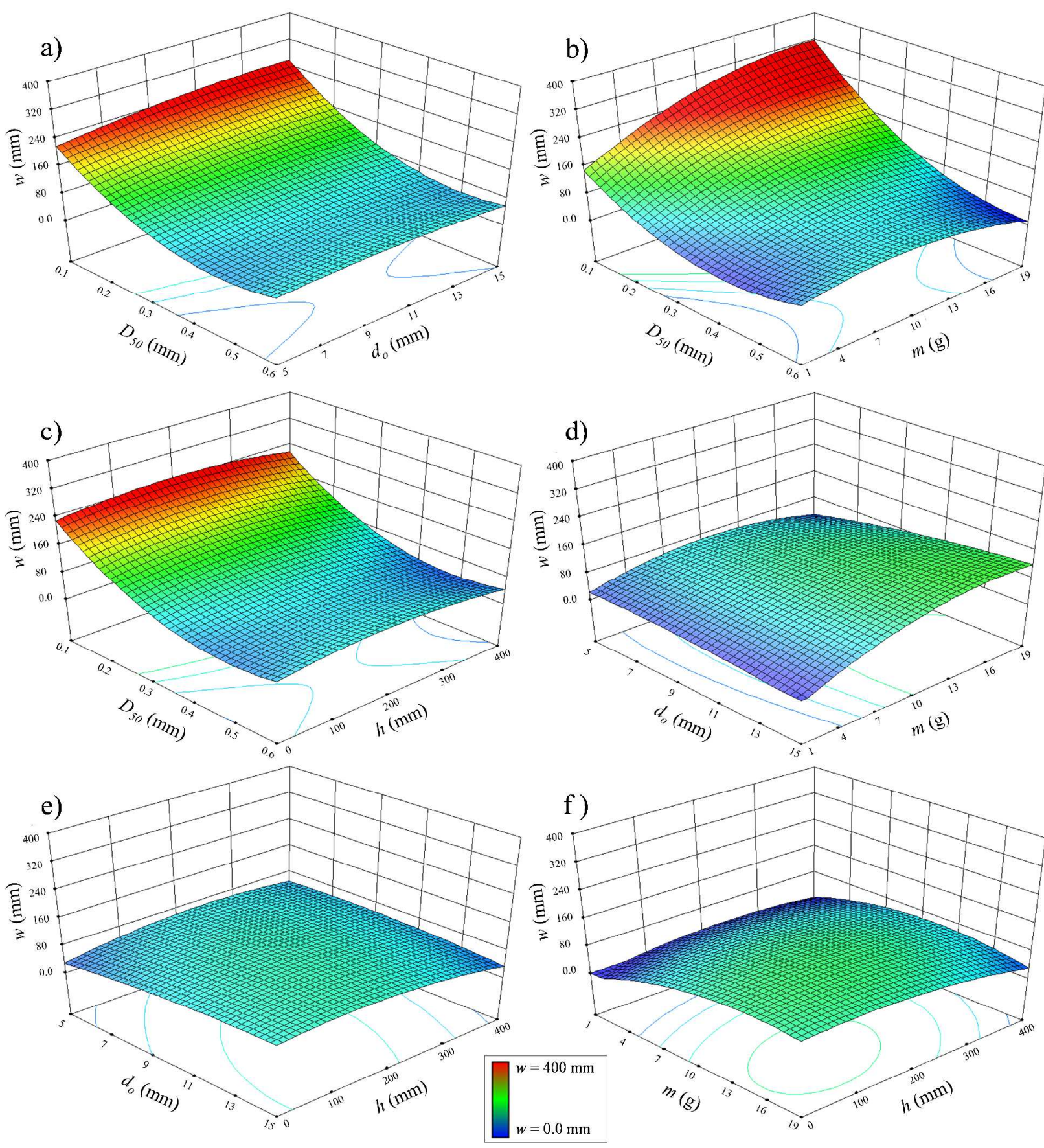

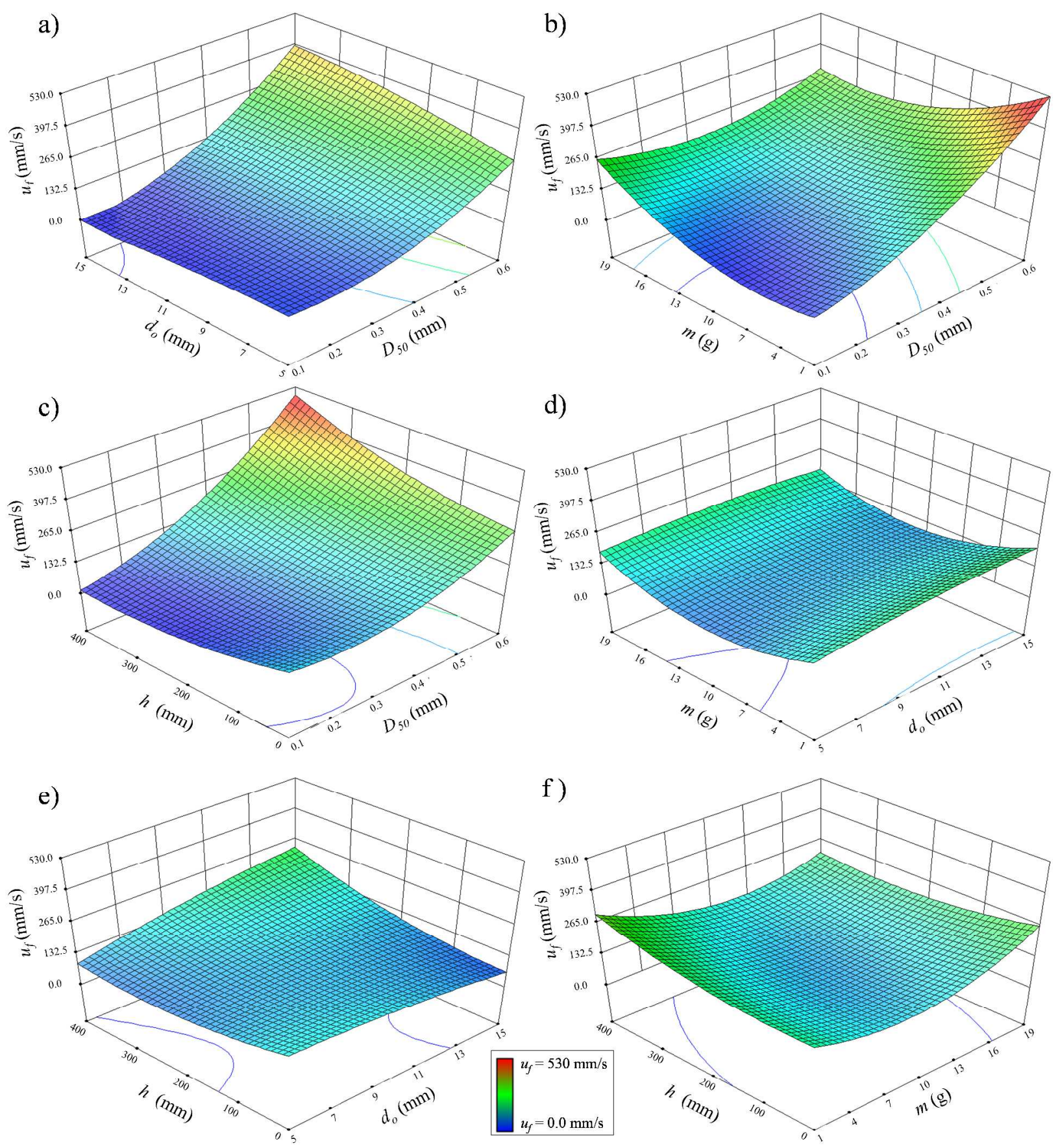